\title{
Task-based language teaching for beginner-level young learners
}

\author{
Rod Ellis \\ Shanghai International Studies University | Curtin University
}

The purpose of this article is to discuss how task-based language teaching (TBLT) can work with beginner-level learners by using input-based tasks. It begins by dismissing a common critique of TBLT, namely that learners need to be taught some language before they can perform tasks, by arguing that input-based tasks make TBLT possible with beginner-level learners and that such an approach is entirely compatible with what research has shown about the early stages of L2 acquisition. A review of the research that has investigated input-based tasks follows and serves to identify key features in the design and implementation of tasks. Designing input-based tasks involves considering the choice of topic, the non-verbal devices that are central to the tasks, the pre-selection of target language, the verbal input for the task, and the task outcomes. Implementation options include task preparation, use of the learners' first language, input modification and elaboration, focus-on-form and feedback, and task repetition.

Keywords: task-based language teaching, beginner learners, input-based tasks, design and implementation

\section{Introduction}

A common critique of task-based language teaching (TBLT) is that it is not suitable for beginner-level learners. Littlewood (2007), for example, argued that learners need to be taught some language before they can take part in a task. Swan (2005) claimed that beginner level learners "urgently need a simple grammatical repertoire" (p.394) and dismissed the claim of second language acquisition researchers, including myself, that grammar is not necessary for beginners.

This common critique derives from a misconception about TBLT, namely that it inevitably (and only) involves the use of speaking tasks. Consider what Swan had to say: 
Learners can hardly make the 'occasional shift in attention to linguistic code features' recommended by Long and Robinson (1998:23) if they know so little basic grammar that they cannot produce discourse to shift from.... basic structures are needed all the time as learners struggle to talk about themselves, their surroundings and their experiences.

Swan's argument is that learners need to be taught some grammar so that they are able to participate in the 'talk' where focus-on-form - an essential feature of TBLT - can take place. He was right to recognize the importance of focus-onform in TBLT but he is guilty of a double misunderstanding here. First, he failed to recognize that 'talk' need not involve learners speaking; they can participate in talk by demonstrating their understanding of what is said to them non-verbally or by using the first language ( $\left.\mathrm{L}_{1}\right)$. Second, focus-on-form is not restricted to discourse where learners speak; it can occur in the input they are exposed to, for example when linguistic forms are enhanced to encourage noticing. Once it is recognized that TBLT can include input-based tasks (i.e. tasks involving learners listening or reading) Swan's objection has no merit. TBLT is possible with beginners but only if it is recognized that it does not always have to involve learner production.

It is not so surprising that critics like Littlewood and Swan have assumed that tasks always involve production. Much of the pedagogic literature on TBLT (e.g. Willis, 1996; Willis \& Willis, 2007) focuses on production (predominantly speaking) tasks. The research literature (e.g. Ellis, 2003; Samuda \& Bygate, 2008) is also overwhelmingly about speaking tasks. The theories that have informed TBLT Long's Interaction Hypothesis and Levelt's model of speaking - have also contributed to the prevailing belief that tasks are speaking tasks. Nevertheless, one of the first definitions of tasks recognized that they can be input-based. Here is the definition from the Longman Dictionary of Applied Linguistics published in 1985:

... any activity or action which is carried out as the result of processing or understanding language (i.e., as a response). For example, drawing a map while listening to a tape, listening to an instruction and performing a command, may be referred to as tasks.

(Richards, Platt, \& Weber, 1985,p.289)

Both of the examples referred to in this definition involve input-based (listening) tasks. Also, pedagogic accounts recognize the importance of tasks that involve no or minimal speaking - especially for beginners. Willis (1996), for example, has a chapter addressing how to teach beginners that includes activities like Yes/ No and Memory Games based on pictures. Ellis (2003) included a chapter on tasks and listening comprehension. Long (2015) includes examples of what he called 'building block' tasks, which involved no or minimal production. So input-based tasks have always had a place in TBLT. Where beginners are concerned they are essential. 
Below I will first review a few findings about early L2 acquisition and then discuss a number of studies that investigated input-based tasks. In the following section I will present a pedagogical account of input-based tasks and in the conclusion address how input-based tasks can prepare learners for speaking tasks.

\section{Early $L_{2}$ acquisition}

The central rationale for TBLT is that it is compatible with how learners acquire an L2. That is, in TBLT L2 acquisition takes place naturally (but with the help of focus-on-form) when learners are engaged in the effort to communicate. TBLT aims to facilitate this process by creating contexts where learners' attention is drawn to linguistic form while they are primarily focused on meaning. In making this claim, TBLT advocates such as Long (2015) and Ellis (2018) do not dispute the fact that learners can learn grammatical rules through interventionist teaching of the kind that Swan favours. But they argue that such teaching only impacts on the learners' explicit system and does not promote the development of implicit knowledge, which is fundamental for effective communication. Implicit knowledge emerges only gradually and, to a considerable extent, unsystematically. Implicit learning is the default process - it is how we learn our first language and, although it weakens with age, it is still the main way all learners acquire an L2 as implicit knowledge. TBLT aims to tap into this natural capacity for implicit learning, which in the case of younger learners, who have not yet reached the critical period and so are not "disabled learners" (to borrow Long's (2015, p.41) term), it is the obvious way to proceed.

The initial stage in L2 acquisition is a receptive one. That is, learners listen (and, if they are able to, read), process the input and start to build and store form-function mappings. During this period learners may attempt to speak but often, especially in the case of children, they go through a silent period. Research documenting the silent period is surveyed in Ellis (2008). A good example is Saville-Troike's (1988) study of nine children learning L2 English in a kindergarten classroom. Five of these opted for an extended silent period while the other four spoke using single words or short phrases. Saville-Troike suggested that the silent children were "inner-directed learners" who viewed language learning as an intrapersonal task while the early speakers were "other-directed learners" who viewed learning as an interpersonal, social activity. Even the other-directed learners, however, spent a lot of time listening to the speech around them. Irrespective of whether learners elect to remain quiet of try speaking from the start, it is clear that what is paramount is the input they are exposed to. 
Learners do not call on grammar in order to understand input. They utilize the fundamental pragmatic capacity of every language user - the ability to relate what they hear to the situation in which it occurs and thereby to understand what is said even if they do not know any of the words in an utterance. Beginner learners rely on the Here-and-Now Principle, that is, they assume that the meanings of utterances can be inferred from the situational context. By relating the words they hear or read to their contextualized meanings learners start to match form to meaning and so remember them. Young learners are adept at this due to their capacity for "fast mapping" (Clark, 1993). At this beginning stage, language that is decontextualized will not be understood.

When production starts, learners use the words they have remembered to communicate their needs and their wants. At this point, production is entirely lexical in nature. Klein and Perdue (1997) described what they called the 'pre-basic variety' that arises as learners grapple with a new language. It is characterized by nominal utterance organization (i.e. there are no verbs). Learners' utterances are context-dependent and scaffolded (i.e. constructed over more than one turn). In time the pre-basic variety gives way to the 'basic variety'. Utterances now include verbs but these are not inflected for tense or aspect. Learners are therefore still very reliant on context to get their meanings across but the basic variety is more flexible, enabling them to express more complex ideas by encoding concepts of time and space adverbially. The basic variety is sufficient for everyday communication and Klein and Perdue noted that two thirds of the learners they investigated in their longitudinal study never progressed to the 'post-basic variety' where finite verbal utterance organization finally occurs.

$\mathrm{N}$. Ellis (2002) presents a connectionist account of L2 acquisition. He argues that what learners acquire in the first instance is exemplar-based. The language system develops slowly as a "conspiracy of associations" and is represented as a network of weighted, neural connections. Learners start by picking up chunks from the input they exposed to - combinations of sounds in words and combinations of words in formulaic expressions such as "I don't know" and "Can I have a ___? Gradually they discover the component parts of these chunks and abstract linguistic schemata emerge out of well-established associations, giving learners greater communicative power as they can now construct novel utterances. This process occurs implicitly (i.e. without consciousness) as learners respond to the frequency of linguistic forms in the input they are exposed to. Gradually and nonlinearly they acquire the 'grammar' of the language but this is rule-like rather than rule-based.

These two views of how productive ability in an L2 is acquired are not incompatible. Both seek to account for how learning takes place implicitly and incidentally through communicative opportunities. Both see acquisition as a slow 
process, initially context-dependent but increasingly allowing for context-free use of the language. Both emphasise that acquisition is grounded in lexis and that what is traditionally thought of as 'grammar' arises out of the need to communicate about the there-and-then as well as the here-and-now. Both views are founded on research investigating how an L2 is acquired 'naturally' in situations where leaners are exposed to it in everyday contexts. In addition, of course, learners may also consciously form explicit representations of rules and regularities, especially if they have been exposed to form-focused instruction. But these representations are not readily available in online communication and are not part of true competence.

The question inevitably arises, therefore, as to whether the natural process of acquisition occurs in a classroom context. There is in fact clear evidence that it does. In an early study, R. Ellis (1984) investigated three children's acquisition of English in a classroom in London. To begin with, they were largely silent, one girl completely so but the two boys ventured one-word utterances from early on. Like Klein and Perdue's naturalistic learners, these learners' production began with a verbless pre-basic variety. They constructed utterances by combining separate words, often across turns, and by relying on context to make their meanings clear. Later verbs began to appear, non-finite initially but gradually over time marked for tense and aspect. They also rapidly picked up formulaic sequences, which they used to perform communicative acts that were important for them (e.g. requests, suggestions and apologies). Over time they learned how to modify and extend these formulas. For example, they first acquired "I don't know" - useful because it allowed them to respond to a teacher question that they did not know how to answer - and later "I don't understand", "I don't like" and "I don't want". By identifying the parts of these formulas that were the same and the parts that were different, they arrived at a simple construction (i.e. 'I don't $+x$ )'. The instruction in these children's classrooms was largely communicative in nature but they did receive some form-focused instruction. There was no evidence, however, that they were able to incorporate the grammatical structures they were taught into their communicative speech.

In a more recent study, Cekaite $(2007,2017)$ focused on how young, complete beginners developed interactional competence in a Swedish as a second language classroom. In this year-long study of two girls, Cekaite documented the transition from repetitious and formulaic production to more diverse discourse and the accompanying broadening of their classroom interaction repertoires. The beginning of the school year was characterized by a very basic repertoire - for example, summoning the teacher's attention during individual work on tasks often non-verbally (e.g. by pointing) but also using limited verbal means (e.g. verbs like "titta" (look) and "kom" (come). By the middle of the year, they could connect 
words using the pragmatic principles of discourse organization and a rudimentary syntax. By the end of the year the two girls were able to participate in multiparty conversations with thematically related contributions. Cekaite's research shows "the situated interplay of the novices' emergent language and interactional skills in L2" (p.58). Development was driven by the children's need to participate in classroom discourse and the fact that Swedish was the medium of classroom communication.

In their review of the research that has investigated young learners, Oliver and Azkarai (2017) emphasized that child and adult L2 acquisition are significantly different. The fundamental difference lies in how learners approach the task of learning an L2. Older school learners are more likely to treat the target language as set of linguistic objects (i.e. words, and grammar rules) that can be studied and mastered intentionally. In other words, they treat learning a foreign language in the same way as they treat other school subjects- as a body of declarative information. Young learners, however, come to school with a clear understanding that language is a tool for communicating and, given a chance, will approach a new language accordingly. Task-based language teaching provides such a chance because a central tenet of this approach is that language serves as the means for achieving communicative outcomes. This is why tasks are so important for young learners.

Lightbown (2016), summarising her lifelong work in classroom language learning, commented "it would be hard to find anyone who would argue that 'comprehension' is not the first requirement for second language learning". Inputbased tasks, therefore, ought to comprise a major part of task-based language teaching. In particular, input-based tasks should be the starting point of a taskbased course as they provide space for learners to go through a silent period if they wish to. Also, while input-based tasks do not require production, they do not prohibit it and so afford opportunity for those learners who are keen to try speaking from the outset to do so.

\section{Classroom research investigating input-based tasks}

There are, in fact, surprisingly few classroom-based studies that have investigated input-based tasks. Table 1 provides a summary of six studies. Five of these studies involved young learners, defined as learners at the elementary and secondary school levels. The input-based tasks were all listen-and-do tasks (Ellis, 2001). These require learners to listen to directions or descriptions and to demonstrate their understanding by performing some action (e.g. completing a diagram, selecting the correct card from an array of cards, playing a game such as word 
bingo). The tasks in all the studies in Table 1 were of the focused kind (Ellis, 2003) - that is, they were designed to incorporate pre-selected vocabulary or grammatical features. In this way, it was possible to investigate whether performing the tasks led to the acquisition of these features.

The studies in Table 1 were motivated by both theoretical and pedagogical considerations. A number of them were framed by Long's $(1983,1996)$ Interaction Hypothesis $(\mathrm{IH})$, which posits that the negotiation of meaning that arises when there is a communication problem facilitates both the comprehension of input and the acquisition of new target features. The IH received support in Ellis Tanaka \& Yamazaki (1994), Ellis \& Heimbach (1997) and Ellis \& He (1999). These studies found that interactionally modified input resulted in better comprehension and acquisition than both pre-modified and unmodified input, pointing to the importance of providing learners with the opportunity to negotiate when they do not understand the input. Very young children, however, may experience difficulty in negotiating, preferring to simply remain silent when they fail to comprehend. Both Ellis and Heimbach's and Shintani's studies found that while some of their six-to-seven year old children in their studies actively negotiated, others did not. One advantage of the teacher performing input-based tasks with groups of children (rather than with individual children) is that those children who prefer to remain silent can benefit from listening to the modified input that results from their fellow learners' negotiation. Erlam and Ellis's (2018) study was motivated by a practical concern. They were interested in seeing how a teacher and students who were unused to input-based tasks responded to them. They reported that the teacher was able to implement the tasks effectively and appreciated their suitability for beginner-level learners. Nevertheless, both this teacher and some of her students felt uncomfortable about the lack of explicit information about the target forms. This study raises the key issue of whether there is a role for explicit instruction with input-based tasks.

Another issue addressed in some of these studies was the relative effectiveness of input-based and output-based instruction. Two studies are relevant here. Ellis and $\mathrm{He}$ (1999) included a condition where the learners were asked to produce the target lexical forms and found that this resulted in the acquisition of more words than the pre-modified and interactionally modified conditions. This study, however, involved adult learners who had reached an intermediate level of proficiency and thus could benefit from being pushed to produce the target words. Shintani's (2016) study, in contrast, investigated very young children who were complete beginners. She found that, on balance, those children who received comprehension-based instruction outperformed those who received traditional production-based instruction. 
Most of the studies in Table 1 focused on vocabulary for a number of reasons. One is the ease of testing vocabulary. A more important reason is that - as we have seen - early language acquisition is lexical in nature. Most of the studies investigated beginner-level learners. Also, with two exceptions these studies were short-term experiments and while it is possible for learners to pick up new words from performing a single task, it is not realistic to expect them to acquire new grammatical features, which (as noted above) emerge only gradually over time. However, two of the studies - Shintani \& Ellis (2010) and Shintani (2016) did investigate grammar. Both studies involved the learners repeating the same tasks multiple times, which afforded opportunity for grammar acquisition. The children performing the input-based tasks did acquire one grammatical feature (plural-s) but not another (copula be). Shintani suggested that the tasks only created a functional need for learners to process plural-s. The children in her study had to select from an array of cards that depicted either single or plural referents and could only complete the tasks successfully if they chose the cards that corresponded to the teacher's directions. Copula be occurred frequently in the input but it is a redundant grammatical feature and thus there was no need for the children to pay attention to it when performing the tasks. The studies in Table 1 show that learners can acquire new words from performing input-based tasks and also simple meaning-bearing grammatical features.

Most of the studies were product-oriented. That is, they focused on whether the tasks resulted in comprehension and acquisition. Comprehension was measured by examining whether the learners performed the relevant actions in response to the teacher's directions and descriptions while acquisition was ascertained by means of post-tests. Two studies - Shintani \& Ellis (2010) and Shintani (2016) - also examined the process features evident when the tasks were performed. They were interested in whether input-based and traditional outputbased instruction resulted in different process features and, if so, what the differences were. An analysis of turn-taking features revealed notable differences between the two types of instruction. The traditional output-based instruction consisted of presentation, practice, production (PPP). It resulted in short initiateresponse-feedback exchanges, display questions, tightly controlled turn-taking, choral production, and undeveloped topics. In contrast, the input-based tasks led to longer exchanges, referential questions (including some initiated by the students), opportunity for the students to manage the turn-taking, and a complete absence of choral production. There was also a difference in how repair work was carried out; in the PPP lessons it was almost entirely other initiated and other repaired (by the teacher) while in the input-based lessons it was predominantly self-initiated (by a learner) and other-repaired (by the teacher). Summing up the differences, Shintani (2016) commented: 
The analyses have shown that the design and implementation of tasks in the TBLT group influenced the occurrence and types of conversation, indicating that tasks create contexts that involve meaning-focused, authentic conversations when they are designed and implemented carefully.

(pp.110-111)

The differences between the interactions that occur in task-based and PPP instruction are well established. Shintani's research is noteworthy because it showed that they are evident even when the tasks did not require learners to engage conversationally.

To sum up, studies that have investigated input-based tasks have shown that even learners who are complete beginners are able to comprehend the input and to acquire new language. Furthermore, they are more effective than traditional production-based instruction activities (i.e. PPP). They result in discourse that resembles the discourse found in naturalistic settings, affording learners the opportunity to engage actively with new language. These studies also offer useful ideas for the design and implementation of input-tasks. I will now turn to consider these.

\section{Designing and implementing input-based tasks}

Input-based tasks do not require output from learners but, as already noted, they do not prohibit it. Like all tasks they must satisfy the general criteria for tasks. Ellis and Shintani (2014) specified four criteria that an instructional activity must satisfy to be called a 'task':

1. There must be a primary focus on meaning (i.e. learners should be mainly concerned with decoding and encoding messages not with focussing on linguistic form).

2. There is a 'gap' of some kind that motivates the exchange of information or opinions.

3. Learners have to rely on their own linguistic resources (linguistic and nonlinguistic) in order to complete the task.

4. Learners are primarily engaged in achieving the outcome of the task.

All the tasks in the studies in Table 1 involved a primary focus on meaning (criterion 1). They required learners to comprehend the input provided by the teacher (decoding) and also afforded opportunity for students to signal their nonunderstanding (encoding). They were all information-gap tasks (criterion 2). As Prabhu (1987) noted, opinion gap tasks are too difficult in the early stages of a task-based course, so for beginner learners information-gap tasks are needed. On 


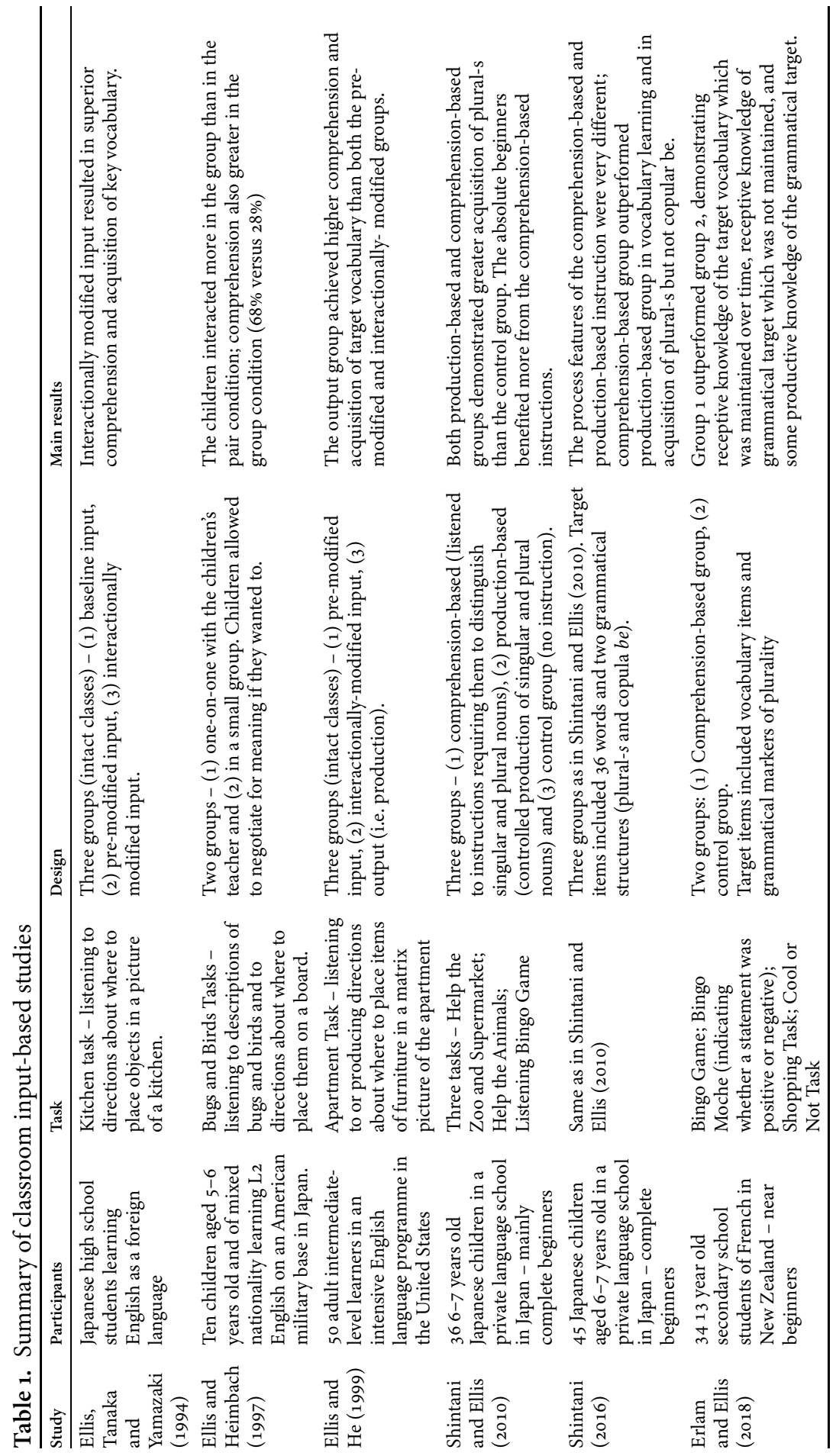


an initial reading, criterion 3 might seem inapplicable to input-based tasks for beginners. In fact it is highly relevant. Beginners lack L2 linguistic resources but they can exploit non-linguistic resources by relating what they hear or read to non-verbal information available from context. The final criterion refers to the task outcome; in the case of input-based tasks the outcome is invariably nonverbal (i.e. it involves performing an action of some kind).

There are surprisingly few pedagogic commentaries on the use of inputbased tasks in language teaching, a further indication of the overriding concern for output-based tasks. Pinter (2015) provides an excellent account of TBLT for young learners and recognizes that TBLT is possible with complete beginners but her examples of tasks are output-based. Long (2015) includes a brief section on what he calls "building block tasks" in a chapter on task-based materials. Duran and Ramaut (2006) provide some interesting examples of input-based tasks for beginning-level learners but these assume that learners have already acquired some target language proficiency. There is very little on input-based tasks for complete beginners.

\subsection{Design of input-based tasks}

Input-based tasks consist of a non-verbal device, linguistic input in the form of directions or descriptions and an outcome, the achieving of which creates the purpose for performing the task. Input-based tasks also have to be about something (i.e. they have a topic). I will begin by considering the choice of topicarguably the starting point in task design - and then consider the kinds of nonverbal devices available to material writers, the target linguistic forms the task could be used to teach, the design of the verbal input, and task outcomes. I will conclude with some comments about task complexity and sequencing.

\section{Choice of task topic}

Long (2015) emphasized the importance of needs analysis to identify the target tasks that are communicatively relevant to learners. However, it is doubtful; whether this is feasible or desirable in the case of beginner learners as there are no obvious target tasks, especially in foreign language contexts where learners have no real need to use the target language outside the classroom. Of greater importance are the other two qualities that Long saw as desirable in pedagogic tasks motivational qualities and "the greatest possible approximation to real world language use" (p.249). Tasks will be motivating if they are interesting to learners, so the question arises how syllabus designers and materials writers can ensure this. Of obvious importance, then, is the choice of topic, which will determine the linguistic content of the task. The topics in the studies in Table 1 were kitchen uten- 
sils, bugs and birds, apartment furniture, a zoo and a supermarket, and clothes. In each case, the topics were chosen by the researchers on the assumption they would be intuitively appealing to the students. A preferred approach, however, might be to consult learners to find out what topic areas they are interested in. Long also talks about the importance of "approximation to real language use" but arguably this depends more on how a task is implemented than on the content of the task and so is considered in the section dealing with task implementation.

\section{Non-verbal devices}

A great variety of non-verbal devices are possible:

- Geometric shapes

- Pictures

- Photos

- Cartoon pictures

- Maps

- Diagrams

- Videos

- Making a model

These devices vary in the amount of detail and therefore the information they contain. For example a very simple geometric shapes task will consist of set of basic shapes (e.g. circle, square, rectangle and triangle), a more complex one that includes the same shapes that are different in size (large; small), a still more complex task one where the shapes differ in terms of both size and colour (red, blue, green etc.). In other words, the challenge that a task poses to learners will depend on the level of detail in the non-verbal device and, therefore, the language that is needed to distinguish one shape from another. The task shown in Table 2 involves pictures of six different women who differ on a number of dimensions - age, hair style and colour, clothes, ethnicity, and what they are doing. Potentially, therefore, this task is quite challenging as it will involve words for all these dimensions. The task could be simplified if the pictures were distinguishable on just one or two dimensions - e.g. a short boy, a tall boy, a short man, a tall man.

The web is a rich source of non-verbal devices for input-based tasks but task designers face the very considerable challenge of selecting those images that pose the right amount challenge for a specific group of learners. To do this they will need to consider the input language that goes with the non-verbal device, which the learners will have to process to achieve the task outcome. 


\section{Choice of target linguistic forms}

The choice of topic and non-verbal device will largely determine the choice of linguistic forms. For example, in Ellis, Tanaka and Yamazaki's study, the key vocabulary in their Kitchen Task included toaster, ladle, scourer, stove and coffee pot. The key items for the Picture Task in Table 2 will depend on how the materials writer wishes to exploit the pictures. For example, one way would be the focus on the words for clothes and colours - purple top, red shoes, blue pants. Another way would be to focus on the actions the women are performing - pointing a finger, taking a photo, holding her hands. The choice of linguistic forms should reflect the learners' stage of development. For complete beginners, items consisting of just noun or adjective + noun - corresponding to the pre-basic variety (Klein \& Perdue, 1997) - would be more suitable while for false beginners items consisting of verb + noun - corresponding to the basic variety - would be possible. Perhaps, though, there is no need for a very tight control of the task language because, as already pointed out, learners have the capacity to infer the meaning of complex linguistic forms from context.

If the aim is to use the task to teach a specific grammatical form, the materials need to be designed accordingly. For example, Shintani decided to teach plural-s and so designed the materials for her Help the Zoo and Help the Supermarket Tasks to include cards depicting single animals and objects (e.g. one squirrel; one battery) and pairs of objects (e.g. two squirrels; two batteries), forcing the learners to listen carefully to decide which card to select. However, given that the early stage of acquisition is predominantly lexical, it would be unwise to attempt to design tasks to try to teach grammatical structures other than very simple ones that have a clear-form-focus mapping. Focused tasks (Ellis, 2009, 2018) have a role to play but later on after learners have acquired a basic proficiency.

\section{Verbal input}

The verbal input is, of course, the core of an input-based task. There are two approaches possible for designing the language the learners will be exposed to. One is to leave it to the teacher to ad lib what to say. The content of the nonverbal device will naturally restrict the language the teacher uses. There are several advantages of this approach. The main one is that it is likely to result in "real-language use", which is the goal of task-based teaching. The teacher is free to experiment with the language he / she chooses, observing how the learners respond to what he / she says and making appropriate online adjustments to suit individual learners. With this approach the verbal input is not 'designed' but rather 'constructed' as the task progresses. How this can be done is considered below when I discuss implementation options. 
The other approach is to prepare a script which teachers can follow when performing the task. For example for the Picture task in Table 2, the script might be as follows:

Write the letter of the woman with a yellow top.

Write the letter of the woman with red shoes.

Write the letter of the woman with yellow hair etc.

A script such as this will be helpful for teachers who lack experience of task-based teaching and, in particular, for teachers who lack confidence and fluency in using the L2. The disadvantage is that the task can become very mechanical and thus less likely to result in "real language use". However, teachers do not need to be tied to the script; they can modify it in accordance with the learners' responses as the task is performed.

\section{Task outcomes}

The outcome of a task is non-verbal - it involves performing a physical action, pointing at a picture, selecting a picture card, or drawing a picture. The outcomes of non-verbal tasks for beginners will take the form of learners' responses to individual input sentences with each response either right or wrong. It would be helpful, however, if the teacher and individual learners were able to see how the task as a whole was performed. This is possible with the Picture Task in Table 2, which requires students to write the letters of the pictures the teacher describes. The teacher can easily check how well the learners did by looking at their task answer sheets This task could also serve as both a teaching and an assessment task. It is also possible to design tasks that have a competitive element. Both Shintani and Erlam and Ellis included a Word Bingo Task. Such tasks are likely to motivate young learners.

\section{Sequencing tasks}

A key issue in the design of any task-based language course, is how to sequence tasks in such a way that they will accumulatively facilitate L2 development. This requires addressing what makes tasks more or less complex as 'complexity' is the criterion traditionally used to sequence tasks. To date, most of the research (e.g. Robinson, 2011) investigating task complexity has only considered output-based tasks and as Long (2016) noted there has been relatively little progress.

Duran and Ramaut (2006) develop a complexity scale for beginner-level tasks that is applicable to input-based tasks. It involves three general parameters - the world represented in the task, the processing demands required for task performance, and the linguistic input features. A simple task is one that involves concrete descriptions, visual support, a high level of redundancy, low 
information-density, understanding information as presented, a non-verbal reaction, high frequency words, short and simple sentences, an explicit structure and a short text. At the other end of the scale a complex task is one that involves an abstract perspective, no visual support, a high density of information and low level of redundancy, an evaluative response to the information that is verbal, low frequency words, long, embedded sentences, an obtuse structure and a long text. The Task in Table 1 is fairly clearly at the simple end of such a scale and obviously tasks for beginner-level learners should be.

Complexity however does not reside solely in the task-as-workplan. Arguably, what is more influential than the design of the task is how it is implemented as teachers can intuitively modify the input - simplifying or complexifying it - as the task unravels according to their perceptions of what the learners are capable of understanding. Complexity is not a fixed quality but rather an emerging one.

\subsection{Implementing an input-based task}

It should be clear from many of my comments in the preceding section, that the effectiveness of an input-based tasks rests to a very large extent on how it is implemented. In this section, therefore, I will identify a number of key features in the effective implementation of input-based tasks. A task is effective if learners are able to understand the input language and achieve the task outcome.

\section{Task preparation}

Task-based lessons, whether involving input or output-based tasks, often have a pre-task stage where learners are prepared for the main task. This is perhaps less necessary in the case of input-based tasks but is an option. For example, in order to prepare students for the Picture Task in Table 2, the teacher could preteach the key words or, better still, ask the learners to find the words needed to describe the pictures in the task by themselves. Another possibility is to pre-teach the grammatical structure that is the focus of a task. Shintani, for example, could have given the learners in her study examples of singular and plural nouns and pointed out how the absence or presence of /s/ on the noun shows whether there is one or more than one. In fact, she did not do this, preferring to let the learners induce the meaning of /s/ as the task progressed. There is an obvious danger in pre-teaching the grammatical target and some TBLT advocates (e.g. Long, 2015) reject it entirely. The risk is that task will lose its 'taskness' because learners end up focusing on form rather on meaning with a consequential loss in the real world use of language. This is, however, less of a danger with the pre-teaching of vocabulary. The remaining options will address the implementation of the main task. 
Table 2. Pictures task

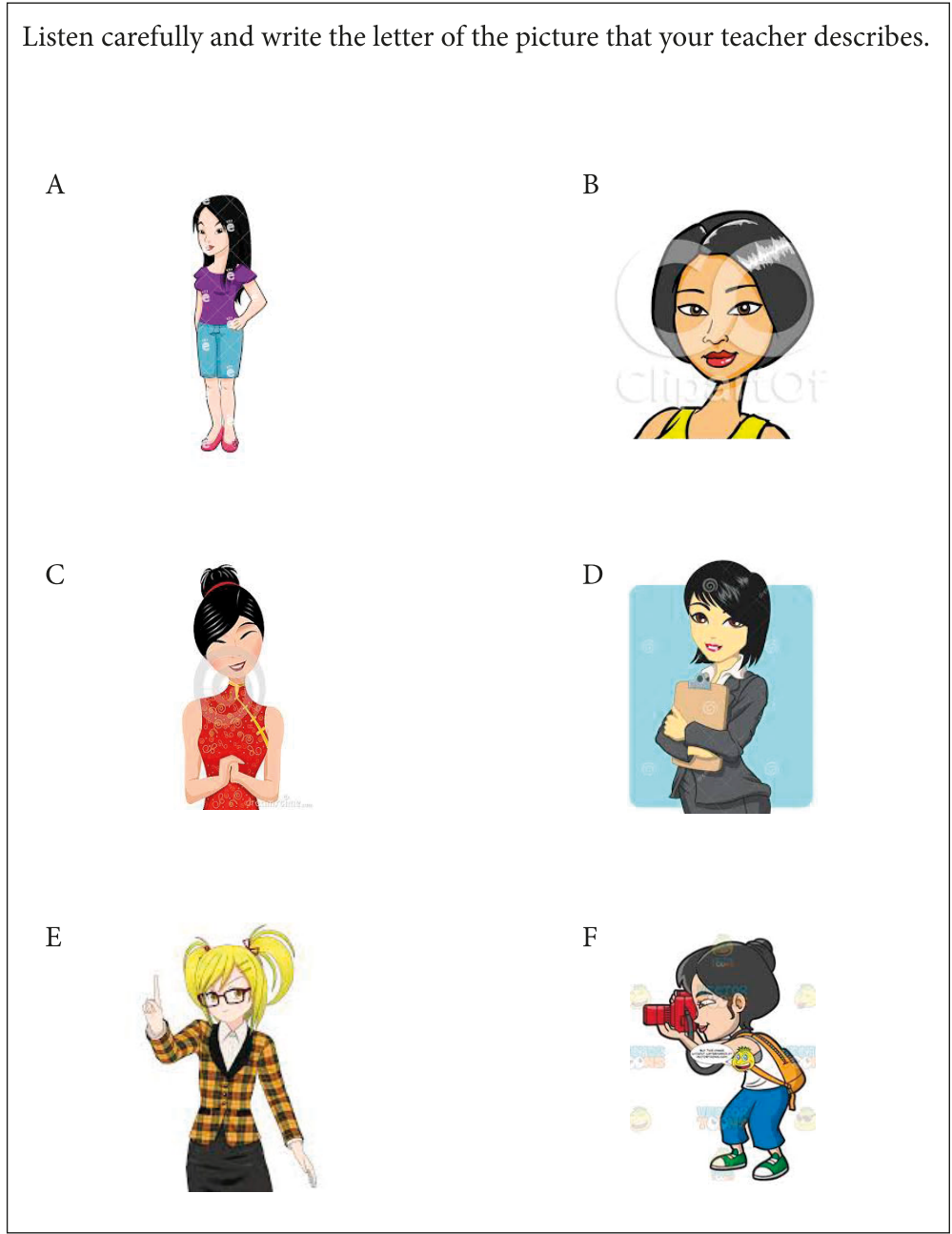

2. Use of the $L_{1}$

The aim of input-based tasks is to expose learners to the target language. For this reason, the teacher should make maximal use of the target language and minimal use of the learners' L1. Obviously the task input must be in the target language but also, ideally, so should the task instructions and classroom management language. The latter involve typical routines that are context-embedded so learners can very rapidly latch onto their meanings. There is, however, a case for the teacher making selective use of the L1. The extract below from the very first English lesson with the Helping the Zoo Task illustrates how this can be done. The teacher starts by using the target language (English) but resorts to Japanese in 
turn (7) when she realizes that the students do not understand 'zoo' but then rapidly returns to English in the same turn.

\section{Extract 1.}

1. T: okay next one. okay? next one. please take the squirrels to the zoo.

2. S3: dobutsu [animal]?

3. T: squirrel to the zoo.

4. S5: squirrel

5. T: yes, that's right. that's right.

6. S2: dobutsu [animal]?

7. T: yeah (.) I said zoo right? zoo. dobutsuen ni iku to iukotowa [going to the zoo means]. otosanaide [don't drop it]. okay. squirrels. squirrels. ready? three (.) two (.) one (.) go.

8. Ss: (showing their cards but no one was correct)

9. T: squirrels. squirrels. that's a crocodile. squirrels are this one. listen. squirrels are these ones. put them into the rubbish box.

(Shintani, 2012)

This extract also illustrates the learners' use of the L1. Complete beginners - such as these learners - will not be able to speak in English at the start but they need to participate actively in the task and can only do so using their L1. Interaction between teacher and students at this stage is only possible if the students use their L1, which plays an essential role in providing the teacher with feedback about whether the learners have understood what she has said in English. Without this feedback there would be no negotiation of meaning and the teacher would not know whether to adjust her input. Shintani found, however, that over time, the children automatically reduced their use of the L1 and began to speak in English. This occurred because the tasks - and how she implemented them - created a natural context for the use of English.

\section{Input modification}

Irrespective of whether the teacher is provided with an input script or creates her own script as the task evolves, there is a need for the teacher to play close attention to the learners' responses as these will signal whether she needs to adjust her input to help them comprehend. The extract above illustrates some of the modification strategies that teachers can use. One is repetition. The key word in the stimuli that initiates this exchange is 'squirrels'. The students fail to understand it. The teacher's response is to repeat it - altogether 'squirrels' is repeated six times. A key driver of acquisition is input frequency (N. Ellis, 2002) so this natural repetition of individual words is likely to be very helpful to beginner learners. Another strategy is simplification. The teacher begins with the full direction ("please take the squirrels to the zoo") but then shortens it in turn (3) to "squir- 
rel to the zoo". This enables student 5 to latch onto the key word and repeat it. The modification strategies that teachers can employ are much the same as those found in foreigner talk - the talk that native speakers use when communicating with non-native speakers of limited proficiency. They are part and parcel of a speaker's communicative competence and are activated automatically once the speaker sees there is a communication problem. They help learners to segment the stream of input they are exposed to and to pick out key words.

\section{Input elaboration}

One of Long's (2015) methodological principles for task-based teaching is "Elaborate Input". He commented:

The principal motivation for elaboration is that elaborated input is psycholinguistically more appropriate than either genuine or simplified input. It is better tuned to the learner's current processing capacity than genuine input and is more likely to be learnable.

Thus as well as simplifying input, the teacher needs to be on the look-out for opportunities to elaborate it. This can also happen quite naturally. Performing an input-based task will necessitate task-essential language and also provide opportunities for task-optional language (i.e. additional language that helps to facilitate learners' understanding). The effective implementation of an input-based task will inevitably require the teacher to elaborate her input using task-optional language. The performance of Shintani's tasks, for example, led to the teacher using adjectives (e.g. names of colours; big and small) to help the learners identify the specific animals or objects in her directions. In addition to investigating whether the learners acquired the task-essential words, Shintani also assessed whether they had acquired the task-optional words she had used and found that indeed they had. Moreover, the superiority she reported for the task-based instruction over the traditional PPP instruction was more clearly evident in the task-optional than task-required words. Teachers need to take care not to overwhelm beginner learners with input but they also do not need to restrict themselves to task-essential language. The aim is to create an acquisition-rich context and this requires learners being exposed to rich input.

\section{Focus-on-form and feedback}

Focus-on-form "overtly draws students' attention to linguistic elements as they arise incidentally in lessons whose overriding focus is on meaning or communication" (Long, 1991, p.45-46). It is an essential feature of task-based teaching because when there is a focus on meaning only, learners may fail to pay attention to form. While this is perhaps less likely in the case of young children it is very 
likely with older, post-critical period children. How then does focus-on-form occur in the performance of input-based tasks? It can be induced proactively by pre-teaching target items but Long (2015) is adamant that it should occur only reactively (i.e. in response to the learner) and this is clearly the best way with young children. Extract 2 from Shintani \& Ellis (2010) illustrates how this is done. The teacher's direction instructs the learners to find the card showing a single toothbrush. The students, however, have become aware from previous directions that they need to work out whether the direction refers to one or two objects so a student immediately initiates a request for confirmation in turn (2). This results in the students repeatedly checking if they have understood. The whole extract serves to focus learners attention' on whether the noun is singular and plural. It demonstrates two important points: the need for the learners to persist in negotiating until they do understand and the teacher's use of a variety of strategies to draw attention to form (e.g. use of numerals; contrasting singular and plural forms; signalling meaning mimetically).

\section{Extract 2.}

1. Teacher: Okay, next one. Please take the toothbrush. Toothbrush.

2. Student 2: One?

3. Teacher: Toothbrush. One toothbrush, two toothbrushes.

4. Student 2: Two?

5. Teacher: No, no, no. Toothbrush, toothbrush.

6. Student 1: (Indicating two with fingers) two-thbrush?

7. Teacher: Not two. One toothbrush.

8. Student 2: Eh? One, two, brush?

9. Teacher: No, no (indicating 'one' with fingers) toothbrush. One toothbrush. Ready, ready? Three, two, one. Go. One toothbrush.

10. All students: (Showing correct cards).

(Shintani \& Ellis, 2010, p. 632)

With output-based tasks, focus-on-form typically involves corrective feedback (i.e. feedback directed at showing learners they have used a linguistic form incorrectly). With input-based tasks, feedback functions differently. Its main function is to let the learners know when they have successfully understood the input stimulus and when they haven't. A secondary function - clearly illustrated in Extract 2 - is to inform the learners whether their guesses about the meaning of the input stimulus are right or wrong. Guessing plays a major role in learners' responses to the input stimulus and neither comprehension nor learning can occur without feedback. 


\section{Task repetition}

A number of studies have pointed to the usefulness of repeating a task - see, for example, Bygate (2018). By and large, though, these studies investigated the repetition of output-based tasks. The only study to date that has looked at the repetition of input-based tasks is Shintani (2012). Shintani asked complete beginners to repeat the same tasks 9 times over a five week period. She found that although the same 'tasks' were repeated the 'activity' involved in performing them changed markedly. She reported that the nature of the teacher's input altered; over time she reduced her use of the L1, her utterances became longer and she elaborated the input more. The learners' use of language also changed; for example, while their private speech remained constant, their social speech increased incrementally and, as might be expected as they became familiar with the tasks, their metatalk reduced. An obvious danger of repeating tasks is that learners will lose interest in them. However, this did not happen. The children remained motivated in performing them throughout. One reason for this is that initially the tasks were very challenging but became more manageable with each repetition. The learners' comprehension improved over time so they could see that they were learning, which also helped to maintain their motivation.

Task repetition is a powerful option with young children although with older children (e.g. secondary level) it may be less effective. The number of times to repeat a task will depend on the task and the students. A general principle that might guide decision-making is whether repeating a task results in different activity. Once the task becomes very easy, the activity as well as the task will become the same and nothing will be gained.

\section{Summary and conclusion}

In this article, I have made the case for the use of input-based tasks with beginnerlevel young learners. I have argued that the common objection that task-based instruction is not possible with beginners is mistaken as learners can complete input-based tasks successfully without having to speak in the target language. I also argued that the use of input-based tasks is compatible with what we know about the early stage of L2 acquisition, namely that it takes place receptively when learners comprehend input and attend to linguistic forms in it. When learners begin to speak they do so using single words (nouns and adjectives) and short formulaic expressions. Input-based tasks cater to this, not be requiring learners to speak, but by allowing them to do so when they are ready. Those learners who prefer to remain silent can do so. 
Although the research into input-based tasks is limited, its results are encouraging. Learners acquire new vocabulary and also simple grammatical features such as plural-s. The elaborated input that results from the teacher performing an input-based task facilitates the acquisition of not just task-essential language but also task-optional language. Furthermore, there is some evidence to suggest that input-based tasks may be more effective than traditional PPP instruction.

I have presented suggestions for the design and implementation of tasks, which are summarised in Table 3. I emphasized that while care is needed in designing suitable tasks, it is how they are implemented that is crucial. A task may be challenging - indeed it should be -but it can be made to work effectively through skilful implementation.

Table 3. Factors to consider in the design and implementation of input-based tasks

\begin{tabular}{ll}
\hline Design variables & Implementation \\
\hline Choice of topic & Task preparation \\
Non-verbal devices & Use of the L1 \\
Choice of linguistic forms & Input modification \\
Verbal input & Input elaboration \\
Task outcomes & Focus-on-form \\
& Task repetition \\
\hline
\end{tabular}

The focus of this article has been entirely on input-based tasks as the best (and arguably the only) way to do task-based language teaching with beginners. An important question, however, is when and how to start introducing outputbased tasks. The obvious answer is to delay until the learners have started to try to speak. One effective strategy for making the switch is to ask students to first complete an input-based task and then try a related output-based tasks. In other words, the input-based task becomes a preparation for the output-based task. For example, the teacher might begin by completing the Picture Task shown in Table 1 and then convert the task into an information-gap task which the students perform in pairs. Lai, Zhao and Wang (2012) provide some useful examples of how input-based tasks can be used to prepare for output-based tasks. There is, however, an obvious need for research that investigates the switch from input-based to output-based tasks. This will necessitate longitudinal studies of beginner-level learners. As I have already noted such studies are sorely lacking. 


\section{References}

Bygate, M. (2018). Learning through task repetition. Amsterdam: John Benjamins. https://doi.org/10.1075/tblt.11

Cekaite, A. (2007). A child's development of interactional competence in a Swedish L2 classroom. Modern language Journal, 9, 45-62. https://doi.org/10.1111/j.1540-4781.2007.00509.x

Cekaite, A. (2017). What makes a child a good language learner? Interactional competence, identity and immersion in a Swedish classroom. Annual Review of Applied Linguistics, 37, 45-61. https://doi.org/10.1017/So267190517000046

Clark, E. (1993). The lexicon in acquisition. Cambridge: Cambridge University Press. https://doi.org/10.1017/CBO9780511554377

Duran, G. \& Ramaut, G. (2006). Tasks for absolute beginners and beyond: Developing and sequencing tasks at basic proficiency levels. In K. Van den Branden (Ed.), Task-based language education: From theory to practice (pp. 47-75). Cambridge: Cambridge University Press. https://doi.org/10.1017/CBO9780511667282.004

Ellis, N. (2002). Frequency effects in language processing. Studies in Second Language Acquisition, 24(2), 143-188. https://doi.org/10.1017/S0272263102002024

Ellis, R. (1984). Formulaic speech in early classroom second language development. In J. Handscombe, R. Orem, \& B. Taylor (Eds.), On TESOL'83: The question of context (pp. 53-66). Washington DC: TESOL.

Ellis, R. (2003). Task-based language learning and teaching. Oxford: Oxford University Press.

Ellis, R. (2001). Non-reciprocal tasks, comprehension and second language acquisition. In M. Bygate, P. Skehan, \& M. Swain (Eds.), Researching pedagogic tasks second language learning, teaching and testing (pp. 49-74). Harlow: Longman Pearson.

Ellis, R. (2008). The study of second language acquisition (2nd ed.). Oxford: Oxford University Press.

Ellis, R. (2009). Task-based language teaching: Sorting out the misunderstandings. International Journal of Applied Linguistics, 19, 221-246. https://doi.org/10.1111/j.1473-4192.2009.00231.x

Ellis, R. (2018). Towards a modular language curriculum for using tasks. Language Teaching Research. https://doi.org/10.1177/1362168818765315

Ellis, R., \& He, X. (1999). The roles of modified input and output in the incidental acquisition of word meanings. Studies in Second Language Acquisition, 21, 285-310. https://doi.org/10.1017/S0272263199002077

Ellis, R., \& Heimbach, R. (1997). Bugs and birds: Children's acquisition of second language vocabulary through interaction. System, 25, 247-259. https://doi.org/10.1016/S0346-251X(97)00012-2

Ellis, R., \& Shintani, N. (2014). Exploring language pedagogy through second language acquisition research. Abingdon: Routledge.

Ellis, R., Tanaka, Y., \& Yamazaki, A. (1994). Classroom interaction, comprehension and the acquisition of word meanings. Language Learning, 44, 449-91. https://doi.org/10.1111/j.1467-1770.1994.tbo1114.x

Erlam, R., \& Ellis, R. (2018). Task-based language teaching for beginner-level learners of L2 French: An exploratory study. Canadian Modern Language Review, 74(1), 1-26. https://doi.org/10.3138/cmlr.3831 
Klein, W., \& Perdue, C. (1997). The basic variety (or: Couldn't natural languages be much simpler?). Second Language Research, 13(4), 301-347.

https://doi.org/10.1191/026765897666879396

Lightbown, P. (2016). From language learner to language learning researcher. In R. Ellis (Ed.), Becoming and being an applied linguist (pp. 175-212). Amsterdam: John Benjamins. https://doi.org/10.1075/z.203.08lig

Littlewood, W. (2007). Communicative and task-based language teaching in East Asian classrooms. Language Teaching, 40, 243-249. https://doi.org/10.1017/S0261444807004363

Lai, C., Zhao, Y., \& Wang, J. (2012). Task-based language teaching in online ab initio foreign language classrooms. Modern language Journal 95(Supplementary Issue), 81-103.

Long, M. (1983). Native-speaker/non-native speaker conversation and the negotiation of comprehensible input. Applied Linguistics, 4, 126-41. https://doi.org/10.1093/applin/4.2.126

Long, M. (1991). Focus on form: A design feature in language teaching methodology. In K. de Bot, R. Ginsberg, \& C. Kramsch (Eds.), Foreign language research in cross-cultural perspective (pp. 39-52). Amsterdam: John Benjamins. https://doi.org/10.1075/sibil.2.07lon

Long, M. (1996). The role of the linguistic environment in second language acquisition. In W. Ritchie \& T. Bhatia (Eds.), Handbook of second language acquisition (pp. 121-158). San Diego, CA: Academic Press.

Long, M. (2015). Second language acquisition and task-based language teaching. Malden, MA: Wiley Blackwell.

Long, M.H. (2016). In defence of tasks and TBLT: Nonissues and real issues. Annual Review of Applied Linguistics, 36, 5-33. https://doi.org/10.1017/S0267190515000057

Long, M., \& Robinson, P. (1998). Focus on form: Theory, research, and practice. In

C. Doughty \& J. Williams (Eds.), Focus on form in classroom second language acquisition (pp. 15-63). Cambridge: Cambridge University Press

Oliver, R., \& Azakarai, A. (2017). Review of child second language acquisition (SLA):

Examining theories and research. Annual Review of Applied Linguistics, 37, 62-76. https://doi.org/10.1017/S0267190517000058

Pinter, A. (2015). Task-based learning with children. In J. Bland (Ed.), Teaching English to young learners. London: Bloomsbury.

Prabhu, V.S. (1987). Second language pedagogy. Oxford: Oxford University Press.

Richards, J., Platt, J., \& Weber, H. (1985). Longman dictionary of applied linguistics. Harlow: Longman.

Robinson, P. (2011). Second language task complexity, the Cognition Hypothesis, language learning, and performance. In P. Robinson (Ed.), Second language task complexity: Researching the cognition hypothesis of language learning and performance (pp. 3-38). Amsterdam: John Benjamins. https://doi.org/10.1075/tblt.2.05ch1

Samuda, V., \& M. Bygate. (2008). Tasks in second language learning. Houndmills: Palgrave MacMillan. https://doi.org/10.1057/9780230596429

Saville-Troike, M. (1988). Private speech: Evidence for second language learning strategies during the 'silent' period. Journal of Child Language, 15(3), 567-90. https://doi.org/10.1017/S0305000900012575

Shintani, N. (2012). Repeating input-based tasks with young beginner learners. RELC Journal, 43(1), 39-51. https://doi.org/10.1177/0033688212439322

Shintani, N. (2016). Input-based tasks in foreign language instruction for young learners. Amsterdam: John Benjamins. https://doi.org/10.1075/tblt.9 
Shintani, N., \& Ellis, R. (2010). The incidental acquisition of plural-s by Japanese children in comprehension-based lessons: A process-product study. Studies in Second Language Acquisition, 32(4), 607-637. https://doi.org/10.1017/S0272263110000288

Swan, M. (2005). Legislating by hypothesis: The case of task-based instruction. Applied Linguistics, 26, 376-401. https://doi.org/10.1093/applin/amio13

Willis, J. (1996). A framework for task-based learning. Harlow: Longman.

Willis, D., \& Willis, J. (2007). Doing task-based teaching. Oxford: Oxford University Press.

\section{Address for correspondence}

\section{Rod Ellis}

Curtin University, Perth, Australia

47/1 Sheen Street

Subiaco, WA 6008

Australia

roderick.ellis@curtin.edu.au

\section{Biographical note}

Rod Ellis is currently a research professor in Curtin University, Perth Australia. He is also a visiting professor at Shanghai International Studies University and an Emeritus Distinguished Professor of the University of Auckland. He has recently been elected as a fellow of the Royal Society of New Zealand. He has written extensively on second language acquisition and taskbased language teaching. His most recent book is Reflections on Task-Based Language Teaching (2018) published by Multilingual Matters. 